\title{
A framework for remission in SLE: consensus findings from a large international task force on definitions of remission in SLE (DORIS)
}

\author{
Ronald van Vollenhoven, ${ }^{1,2}$ Alexandre Voskuyl, ${ }^{2}$ George Bertsias, ${ }^{3}$ Cynthia Aranow, ${ }^{4}$ \\ Martin Aringer, ${ }^{5}$ Laurent Arnaud, ${ }^{1}$ Anca Askanase, ${ }^{6}$ Petra Balážová, ${ }^{7}$ Eloisa Bonfa, ${ }^{8}$ \\ Hendrika Bootsma, ${ }^{9}$ Dimitrios Boumpas, ${ }^{10}$ lan Bruce, ${ }^{11}$ Ricard Cervera, ${ }^{12}$

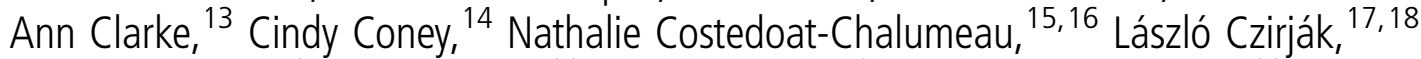 \\ Ronald Derksen, ${ }^{19}$ Andrea Doria, ${ }^{20}$ Thomas Dörner, ${ }^{21}$ Rebecca Fischer-Betz, ${ }^{22}$ \\ Ruth Fritsch-Stork, ${ }^{19}$ Caroline Gordon, ${ }^{23}$ Winfried Graninger, ${ }^{24}$ Noémi Györi, ${ }^{1}$ \\ Frédéric Houssiau, ${ }^{25}$ David Isenberg, ${ }^{26}$ Soren Jacobsen, ${ }^{27}$ David Jayne, ${ }^{28}$ \\ Annegret Kuhn, ${ }^{29}$ Veronique Le Guern, ${ }^{15,16}$ Kirsten Lerstrøm, ${ }^{30}$ Roger Levy, ${ }^{31}$ \\ Francinne Machado-Ribeiro, ${ }^{31}$ Xavier Mariette, ${ }^{32}$ Jamil Missaykeh, $^{33}$ Eric Morand $^{34}$ \\ Marta Mosca, ${ }^{35}$ Murat Inanc, ${ }^{36}$ Sandra Navarra, ${ }^{37}$ Irmgard Neumann, ${ }^{38}$ \\ Marzena Olesinska, ${ }^{39}$ Michelle Petri, ${ }^{40}$ Anisur Rahman, ${ }^{26}$ Ole Petter Rekvig, ${ }^{41}$ \\ Jozef Rovensky, ${ }^{42}$ Yehuda Shoenfeld, ${ }^{43}$ Josef Smolen, ${ }^{44,45}$ Angela Tincani, ${ }^{46}$ \\ Murray Urowitz, ${ }^{47}$ Bernadette van Leeuw, ${ }^{30}$ Carlos Vasconcelos, ${ }^{48}$ Anne Voss, ${ }^{49}$ \\ Victoria P Werth, ${ }^{50,51}$ Helena Zakharova ${ }^{52}$ Asad Zoma, ${ }^{53}$ Matthias Schneider, ${ }^{22}$ \\ Michael Ward ${ }^{54}$
}

Handling editor Tore K Kvien

- Additional material is published online only. To view please visit the journal online (http://dx.doi.org/10.1136/ annrheumdis-2016-209519)

For numbered affiliations see end of article.

Correspondence to Dr Ronald van Vollenhoven, Amsterdam Rheumatology and Immunology Center ARC, Amsterdam, 1100 DD, The Netherlands: r.f.vanvollenhoven@amc.uva.n

Received 9 March 2016 Revised 25 September 2016 Accepted 22 October 2016 Published Online First 24 November 2016

\section{ABSTRACT}

Objectives Treat-to-target recommendations have identified 'remission' as a target in systemic lupus erythematosus (SLE), but recognise that there is no universally accepted definition for this. Therefore, we initiated a process to achieve consensus on potential definitions for remission in SLE.

Methods An international task force of 60 specialists and patient representatives participated in preparatory exercises, a face-to-face meeting and follow-up electronic voting. The level for agreement was set at $90 \%$.

Results The task force agreed on eight key statements regarding remission in SLE and three principles to guide the further development of remission definitions:

1. Definitions of remission will be worded as follows: remission in SLE is a durable state characterised by routine labs)

2. For defining remission, a validated index must be used, for example, clinical systemic lupus erythematosus disease activity index (SLEDAI)=0, British Isles lupus assessment group (BILAG) 2004 D/E only, clinical European consensus lupus outcome measure $(E C L A M)=0$; with routine laboratory assessments included, and supplemented with physician's global assessment.

3. Distinction is made between remission off and on therapy: remission off therapy requires the patient to be on no other treatment for SLE than maintenance antimalarials; and remission on therapy allows patients to be on stable maintenance antimalarials, low-dose corticosteroids (prednisone $\leq 5 \mathrm{mg} /$ day), maintenance immunosuppressives and/or maintenance biologics.
The task force also agreed that the most appropriate outcomes (dependent variables) for testing the prognostic value (construct validity) of potential remission definitions are: death, damage, flares and measures of health-related quality of life.

Conclusions The work of this international task force provides a framework for testing different definitions of remission against long-term outcomes.

\section{INTRODUCTION}

Outcomes in systemic lupus erythematosus (SLE) have improved considerably over the past decades. For the most widely studied specific organ involvement in SLE, lupus nephritis, results from clinical trial follow-up studies demonstrate that the longterm renal survival in this condition has now improved to $>90 \% .{ }^{1}$ However, not all outcomes in SLE show the same favourable trends. Most notably, the overall health-related quality of life (HR-QoL) for patients with SLE remains reduced. ${ }^{2}$ This and other considerations prompted the initiation of the treat-to-target for SLE (T2T/SLE), initiative which over the past several years established an international consensus on the approach to the therapy of SLE based on (1) identifying an appropriate target for each patient; (2) initiating treatment steps to try to achieve this target; (3) assessing the target and (4) adjusting the therapeutic approach, if necessary. These elaborations led to the T2T/SLE recommendations published in $2014 .^{3}$ One of the most significant targets in SLE was identified as 'remission of systemic symptoms 
and organ manifestations'. However, it was recognised by the panel that no generally accepted definition of remission in SLE exists today. Such a definition could be important for basic, clinical and epidemiological studies and clinical trials in lupus, and also for clinical practice. The literature on this topic demonstrates that many clinical trials and observational studies have used a large number of different ad hoc definitions of remission; many of these were reviewed in a recent study. ${ }^{4}$ Consequently, the T2T/SLE panel identified the definition of remission as a research priority for SLE. In response, an initiative was undertaken in order to achieve consensus in a large multiparty international task force on potential definitions of remission in SLE (DORIS).

\section{METHODS}

An international task force consisting of rheumatologists, nephrologists, dermatologists, clinical immunologists and patient representatives, totalling 60 individuals, was convened. In March 2014, a preliminary meeting was held by a steering committee consisting of 15 of these representatives. The steering committee identified four domains critical to further development of remission definitions; 10 preliminary statements regarding remission that were felt to be uncontroversial; key controversies and a set of proposed topics for further discussion. During the following 4-month period, the 10 preliminary statements were presented to the full task force electronically, deliberated upon by email and then subjected to formal electronic voting. High-level agreement was readily achieved for eight of these, whereas two were placed on the agenda for the subsequent consensus conference. Moreover, an additional number of key topics were identified during these deliberations that were to be dealt with more thoroughly at the face-to-face meeting.

In August 2014, a consensus conference took place where a large majority of the full task force was present. The explicit goal of this consensus conference was to establish guiding principles for working towards a definition of remission in SLE and to formulate proposed definitions that would be amenable to scientific testing. During this meeting, formal votes were taken on a range of points. The level for agreement was set at $>90 \%$.

\begin{tabular}{|c|c|c|}
\hline & Statement & $\begin{array}{l}\% \text { in } \\
\text { favour }\end{array}$ \\
\hline 1 & Remission is a desirable outcome for the patient with SLE. & 100 \\
\hline 2 & $\begin{array}{l}\text { Remission in SLE includes, at the very least, the absence of } \\
\text { symptoms and signs of SLE. }\end{array}$ & 100 \\
\hline 3 & Remission in SLE is not the same as a cure. & 100 \\
\hline 4 & Remission in SLE is not the same as low disease activity. & 93 \\
\hline 5 & $\begin{array}{l}\text { Remission is a state that, if sustained, is associated with a low } \\
\text { likelihood of adverse outcome. }\end{array}$ & 100 \\
\hline 6 & $\begin{array}{l}\text { 'Serological activity' in SLE generally refers to the presence of } \\
\text { anti-DNA antibodies and/or hypocomplementemia. }\end{array}$ & 100 \\
\hline 7 & $\begin{array}{l}\text { Treatment with antimalarials does not preclude the patient from } \\
\text { being considered to be in remission. }\end{array}$ & 98 \\
\hline 8 & $\begin{array}{l}\text { Treatment with moderate-dose or high-dose steroids does } \\
\text { preclude the patient from being considered in remission. }\end{array}$ & 98 \\
\hline
\end{tabular}

Out of 10 statements selected by the steering committee, 8 achieved $>90 \%$ agreement on electronic voting by the entire task force. Two statements ("A definition of remission SLE must be reasonably consistent with the use of this term in the literature" and "Durability in time can be added to any definition of remission in order to define a 'durable remission' but need not be included in the definition of remission itself") did not achieve consensus and were discussed further at the face-to-face meeting.
The procedure was informed by the results of the systematic literature review that was carried out in the context of the 'T2T/ SLE' project $^{3}$ and was modified and updated in September 2015. We focused on 2 of the 12 original topics of interest that were more relevant to the present study, namely topic \#2 ("Have any definitions for low disease activity and remissionboth global and organ-specific - been validated as surrogates of therapeutic success against damage accrual, mortality and QoL in SLE?") and topic \#5 ("Is sustained reduction of disease activity or prevention of flares-both general and organ-specifican achievable goal in SLE?"). ${ }^{3}$ The literature search was repeated in September 2015 by author GB to include more recently published literature. The PubMed database was searched using index terms and all English-language human studies were evaluated based on the title, abstract and/or fulltext. For the purpose of the present study, we report on the systematic literature review results relevant to remission only, which were published since the year 1990 and included $\geq 70$ patients with SLE.

\section{RESULTS}

\section{Domains considered critical for defining remission in SLE}

Four domains critical for defining remission in SLE were identified: clinical disease activity, serological activity, duration and treatment. Within each of these domains, a number of key issues were identified and these form the basis of the work described here.

\section{Preliminary statements on remission in SLE}

Ten statements, considered highly relevant for developing a definition of remission and expected to be uncontroversial, were prepared by the steering committee and subjected to electronic voting by the task force. Eight of these statements readily achieved a high level of consensus (>90\%) and are shown in table 1.

Therefore, remission is identified as a desirable outcome for patients with SLE with, at the very least, the absence of major symptoms and signs of SLE. Remission is conceived of in terms different from a cure, yet it is also regarded as meaningfully different from a low disease activity state, including the lupus low disease activity state (LLDAS) that has recently been proposed by the Asia-Pacific Lupus Collaboration. ${ }^{5}$ Perhaps most critically for future work in this area, it is recognised that remission, like LLDAS, has to be a state that, if sustained, is associated with a low likelihood of adverse outcome. To this end, the systematic literature review identified a number of observational studies in patients with lupus nephritis, which illustrate that attainment of (complete) renal remission (or response) (typically defined as a very low level of proteinuria, with normal or stable renal function, with or without inactive urine sediment) is associated with favourable long-term patient and renal outcomes (table 2). Similarly, in general SLE, three retrospective cohort studies have suggested that patients who achieve disease remission have significantly lower rates of damage accrual or mortality after follow-up.

Specific agreement was also achieved on the definition of 'serological activity,' where it was agreed that there was sufficient support in the literature pertaining to the presence of anti-DNA antibodies and/or hypocomplementemia (defined as above or below the upper limit of normal value for the local laboratory, respectively), but without reference to other autoantibodies. The task force discussed whether definitions of remission should distinguish patients who are serologically active from those who are serologically inactive, as the former are much more likely to experience subsequent flare. ${ }^{49}$ No consensus was reached on that statement and the task force 
Table 2 Validation of published definitions of disease remission against outcomes in SLE (studies with $\mathrm{n} \geq 70$ patients)

\begin{tabular}{|c|c|c|c|c|}
\hline Author (ref.) & N & Remission definition(s) & Remission achieved (\%) & Association of remission with outcomes \\
\hline \multicolumn{5}{|l|}{ General SLE } \\
\hline Drenkard et $a l^{6}$ & 667 & $\begin{array}{l}\geq 1 \text { year of clinically inactive disease (serological activity } \\
\text { allowed) that permitted withdrawal of all lupus drugs }\end{array}$ & $23.4 \%$ & $\begin{array}{l}\text { 12.5-fold reduced risk for death (follow-up } 11.6 \\
\pm 6.0 \text { years), after controlling for effects of renal } \\
\text { disease and thrombocytopenia }\end{array}$ \\
\hline Nossent et al $l^{7}$ & 200 & $\begin{array}{l}\text { Physician judgement (not otherwise specified), assessed } \\
\text { during the first year of disease }\end{array}$ & $27.5 \%$ & $\begin{array}{l}\text { Lower annual relapse rates, lower average SLEDAI, } \\
\text { lower cumulative SDI scores at the end of 5-year } \\
\text { follow-up }\end{array}$ \\
\hline Zen et $a l^{8}$ & 224 & $\begin{array}{l}\geq 5 \text { years complete remission with SLEDAI-2K=0 (HCQ } \\
\text { allowed) or clinical remission with clinical SLEDAI- } 2 \mathrm{~K}=0 \\
\text { (serological activity allowed) off-steroids or on low-dose } \\
\text { steroids (HCQ/ISTs allowed) }\end{array}$ & $\begin{array}{l}7.1 \% \text { (complete } \\
\text { remission), } 14.7 \% \\
\text { (off-steroids), } 15.6 \% \text { (on } \\
\text { steroids) }\end{array}$ & $\begin{array}{l}\text { Damage accrual rates (end of 5-year follow-up): } \\
18.8 \% \text { (complete remission), } 18.2 \% \text { (off-steroids), } \\
37.1 \% \text { (on steroids) and } 51.4 \% \text { (no remission) }\end{array}$ \\
\hline $\begin{array}{l}\text { Medina-Quiñones } \\
\text { et } a l^{9}\end{array}$ & 532 & $\begin{array}{l}\geq 3 \text { years with BILAG C, D or E, no serological activity, } \\
\text { off-steroids, off-immunosuppressives (HCQ/NSAIDs } \\
\text { allowed) }\end{array}$ & $14.5 \%$ & $\begin{array}{l}\text { Lower mortality rates ( } 5.2 \% \text { vs } 13.4 \% \text {; median } \\
\text { follow-up } 12 \text { years) }\end{array}$ \\
\hline \multicolumn{5}{|l|}{ Lupus nephritis } \\
\hline Moroni et al $1^{10}$ & 70 & CRR: $\mathrm{UPr}^{*}<0.2$, normal renal function & $38.5 \%$ (at last follow-up) & $\begin{array}{l}\text { CRR was associated with fewer renal flares, better } \\
\text { outcome of renal flares }\end{array}$ \\
\hline Mok et al ${ }^{11}$ & 183 & $\begin{array}{l}\text { CRR: UPr }<0.3 \text {, normal SAlb, normal renal function, } \\
\text { assessed at the end of first year of therapy }\end{array}$ & $64 \%$ & $\begin{array}{l}\text { Lack of CRR was associated (RR 9.9) with } \\
\text { development of ESRD (mean follow-up } 181 \text { months) }\end{array}$ \\
\hline Korbet et $a l^{12}$ & 86 & $\begin{array}{l}\text { CRR: } \mathrm{SCr} \leq 1.4 \mathrm{mg} / \mathrm{dL} \text {, UPr } \leq 0.33 \text {, attained within } 5 \text { years } \\
\text { of entering the study. See also refs } 13,14\end{array}$ & $43 \%$ & $\begin{array}{l}\text { CRR was associated with reduced risk of progression } \\
\text { to ESRD (HR 0.12), increased rates of patient survival } \\
\text { at } 5 \text { and } 10 \text { years (follow-up } 120 \pm 65 \text { months) }\end{array}$ \\
\hline Illei et $a l^{15}$ & 145 & $\begin{array}{l}\text { CRR: } \mathrm{SCr}<130 \% \text { of the lowest level during treatment, UPr } \\
<1 \text {, inactive urine sediment, off IST (HCQ and prednisone } \\
\leq 10 \mathrm{mg} / \text { day allowed), for } \geq 6 \text { months }\end{array}$ & $50.3 \%$ & $\begin{array}{l}\text { Lack of CRR was associated with increased risk for } \\
\text { severe nephritic flare (likelihood ratio (LR) 5.7) and } \\
\text { progression to ESRD (LR 7.0) (median follow-up } 116 \\
\text { to } 123 \text { months) }\end{array}$ \\
\hline Hill et $a l^{16}$ & 71 & CRR: $\mathrm{SCr} \leq 123 \mu \mathrm{mol} / \mathrm{L}, \mathrm{UPr} \leq 0.33$ & $\mathrm{~N} / \mathrm{D}$ & $\begin{array}{l}\text { Lack of CRR was associated with decreased } 10 \text {-year } \\
\text { survival rates from doubling of } \mathrm{SCr}\end{array}$ \\
\hline Mok et al ${ }^{17}$ & 189 & $\begin{array}{l}\text { CRR: stabilised/improved } \mathrm{SCr} \text {, UPr }<1 \text {, improved serum C3 } \\
\text { for } \geq 6 \text { months, assessed at the end of IST }\end{array}$ & $55 \%$ & $\begin{array}{l}\text { Lack of CRR was associated with increased risk (HR } \\
4.5 \text { ) for development of ESRD (mean follow-up } \\
96.5 \text { months) }\end{array}$ \\
\hline Mok et al ${ }^{18}$ & 268 & Same as in ${ }^{17}$ & $59 \%$ & $\begin{array}{l}\text { Lack of CRR was associated with increased risk (HR } \\
4.5) \text { for adverse outcome (doubling of SCr or ESRD or } \\
\text { patient death) }\end{array}$ \\
\hline Moroni et a $\left.\right|^{19}$ & 93 & $\begin{array}{l}\text { CRR: SCr }<1.2 \mathrm{mg} / \mathrm{dL} \text {, stable or } 25 \% \text { increase of baseline } \\
\mathrm{CrCl}, \mathrm{UPr}<0.2 \text {, inactive urine sediment }\end{array}$ & $\begin{array}{l}82 \%(63.4 \% \text { at last } \\
\text { follow-up) }\end{array}$ & $\begin{array}{l}\text { Lack of CRR was associated (RR 4.3) with } \\
\text { development of chronic renal insufficiency (median } \\
\text { follow-up } 181 \text { months) }\end{array}$ \\
\hline Mak et $a l^{20}$ & 149 & $\begin{array}{l}\text { CRR: stabilised/improved } \mathrm{SCr} \text {, improved serum } \\
\text { complement, UPr }<1 \text {, inactive urine sediment for } \\
\geq 6 \text { months, assessed at the end of first year of therapy }\end{array}$ & $60.4 \%$ & $\begin{array}{l}\text { Lack of CRR was associated with renal damage } \\
\text { (mean follow-up } 80 \text { months) }\end{array}$ \\
\hline Lee et $a^{21}$ & 77 & $\begin{array}{l}\text { CRR: } \mathrm{SCr}<1.2 \mathrm{mg} / \mathrm{dL}, \mathrm{UPr}<0.2 \text {, inactive urinary sediment, } \\
\text { for } \geq 6 \text { months }\end{array}$ & $52 \%$ & $\begin{array}{l}\text { Lack of CRR was associated with development of } \\
\text { chronic renal insufficiency and/or death (follow-up } \\
8.3 \pm 4.4 \text { years) }\end{array}$ \\
\hline Sun et $a l^{22}$ & 100 & $\begin{array}{l}\text { CRR: UPr } \leq 0.4 \text {, normal urinary sediment, normal SAlb, } \\
\text { normal SCr }\end{array}$ & $58 \%$ & $\begin{array}{l}\text { Lack of CRR was associated with ESRD (median } \\
\text { follow-up } 60 \text { months) }\end{array}$ \\
\hline Ayodele et $a l^{23}$ & 105 & $\begin{array}{l}\text { CRR: stable }( \pm 25 \%) \text { renal function, } U \operatorname{Pr}<0.2 \text {, assessed at } \\
\text { the end of first year of therapy }\end{array}$ & $44.8 \%$ & CRR was associated with higher mean survival time \\
\hline So et $a l^{24}$ & 117 & $\begin{array}{l}\text { CRR: } \mathrm{SCr} \leq 1.4 \mathrm{mg} / \mathrm{dL}, \mathrm{UPr} \leq 0.5 \text {, inactive urine sediment, } \\
\text { assessed after } 6 \text { months of therapy }\end{array}$ & $50.4 \%$ & $\begin{array}{l}\text { CRR was associated with reduced risk for subsequent } \\
\text { renal flares and chronic renal failure (mean follow-up } \\
66-76 \text { months) }\end{array}$ \\
\hline Reich et $a l^{25}$ & 98 & CRR: SCr $\leq 120 \mathrm{mmol} / \mathrm{L}(1.4 \mathrm{mg} / \mathrm{dL}), \mathrm{UPr}<0.3$ & $74.5 \%$ & $\begin{array}{l}\text { Lack of CRR was associated with faster GFR decline } \\
\text { (follow-up } 12.4 \pm 8.4 \text { years) }\end{array}$ \\
\hline Alsuwaida et $a l^{26}$ & 77 & CRR: $\mathrm{SCr} \leq 125 \mu \mathrm{mol} / \mathrm{L}, \mathrm{UPr} \leq 0.33$ & $41.6 \%$ & $\begin{array}{l}\text { CRR was associated with higher renal survival rate at } \\
10 \text { years. Lower risk for doubling of } \mathrm{SCr}\end{array}$ \\
\hline Dhir et $a^{27}$ & 188 & $\begin{array}{l}\text { UPr reduction by } \geq 50 \% \text { to }<2 \text {, inactive urine sediment, } \\
\text { normal } \mathrm{SCr}(\leq 1.5 \mathrm{mg} / \mathrm{dL}) \text {, assessed at the end of first year }\end{array}$ & $54.6 \% \dagger$ & $\begin{array}{l}\text { Lack of remission was associated (HR 13.8) with } \\
\text { chronic renal failure or death (median follow-up } \\
6 \text { years) }\end{array}$ \\
\hline Moroni et a $\mathrm{l}^{28}$ & 103 & $\begin{array}{l}\text { CRR: } \mathrm{SCr}<1.2 \mathrm{mg} / \mathrm{dL} \text {, stable or } 25 \% \text { increase of baseline } \\
\mathrm{CrCl}, \mathrm{UPr}<0.2 \text {, inactive urine sediment }\end{array}$ & $70.9 \%$ & $\begin{array}{l}\text { CRR was associated with good renal outcome (no } \\
\text { chronic renal insufficiency) (follow-up } 156 \\
\pm 105 \text { months) }\end{array}$ \\
\hline Mahmoud et al ${ }^{29}$ & 135 & $\begin{array}{l}\text { CRR: } \mathrm{SCr} \leq 1.2 \mathrm{mg} / \mathrm{dL} \text {, and } 25 \% \text { increase of baseline } \mathrm{CrCl} \\
\text { if abnormal, or stable value if abnormal at baseline, UPr } \\
<0.2 \text {, inactive urine sediment }\end{array}$ & $59.3 \%$ & $\begin{array}{l}\text { Lack of CRR in the first year was associated with } \\
\text { adverse outcome (death, ESRD or doubling of SCr) }\end{array}$ \\
\hline
\end{tabular}




\begin{tabular}{|c|c|c|c|c|}
\hline Author (ref.) & $\mathrm{N}$ & Remission definition(s) & Remission achieved (\%) & Association of remission with outcomes \\
\hline $\begin{array}{l}\text { Fernandes das } \\
\text { Neves et }\left.a\right|^{30}\end{array}$ & 105 & $\begin{array}{l}\text { CRR: UPr }<0.2 \text {, negative anti-double stranded DNA } \\
\text { antibodies, normal C3 and normal } S C r \text {, for } \geq 5 \text { consecutive } \\
\text { years }\end{array}$ & $38.1 \%$ & $\begin{array}{l}\text { CRR was associated with preservation of normal renal } \\
\text { function }(80 \% \text { vs } 43 \%) \text { and reduced mortality (0\% vs } \\
22 \% \text { ) compared with partial/no remission group } \\
\text { (follow-up } 13.7 \pm 14.1 \text { years) }\end{array}$ \\
\hline Koo et $a l^{31}$ & 193 & CRR: UPr $<0.3$, for $\geq 6$ months & $42.5 \%$ & $\begin{array}{l}\text { CRR was associated with reduced risk of mortality } \\
\text { and ESRD (follow-up } 158 \pm 70 \text { months) }\end{array}$ \\
\hline Dall'Era et $a^{32}$ & 76 & $\begin{array}{l}\text { Different sets of response criteria based on a range of } \\
\text { cut-offs of UPr, SCr and RBCs at 3, } 6 \text { and } 12 \text { months. Best } \\
\text { criterion was } \mathrm{UPr}<0.8 \text { at } 12 \text { months }\end{array}$ & $59.2 \%$ & $\begin{array}{l}\text { Sensitivity } 81 \% \text { and specificity } 78 \% \text { for favourable } \\
\text { long-term ( } 7 \text { years) renal outcome ( } \mathrm{SCr} \leq 1.0 \mathrm{mg} / \mathrm{dL} \text { ). } \\
\text { The LUNAR study remission criterion (UPr } \leq 0.5, \mathrm{SCr} \\
\pm 15 \% \text { of baseline, inactive urine sediment) had } 32 \% \\
\text { sensitivity, } 91 \% \text { specificity }\end{array}$ \\
\hline Tamirou et $a l^{\beta 3}$ & 104 & $\begin{array}{l}\text { Different sets of CR criteria based on levels of UPr, Scr and } \\
\text { urinary RBCs at } 3,6 \text { and } 12 \text { months. Best criterion was } \\
\text { UPr } \leq 0.5 \text { at } 12 \text { months }\end{array}$ & $49.0 \%$ & $\begin{array}{l}\text { Positive predictive value } 92 \% \text { for achieving good } \\
\text { long-term renal outcome ( } \mathrm{SCr} \leq 120 \% \text { of baseline } \\
\text { value) after median } 110 \text { months }\end{array}$ \\
\hline Tamirou et al ${ }^{34}$ & 80 & $\begin{array}{l}\text { Subgroup analysis of. }{ }^{33} \text { Different sets of response criteria } \\
\text { based on a range of cut-offs of UPr, SCr and RBCs at } 3,6 \\
\text { and } 12 \text { months. Best criterion was UPr }<0.7 \text { at } 12 \text { months }\end{array}$ & $63.8 \%$ & $\begin{array}{l}\text { Sensitivity } 71 \% \text { and specificity } 75 \% \text { for favourable } \\
\text { long-term ( } 7 \text { years) renal outcome ( } \mathrm{SCr} \leq 1.0 \mathrm{mg} / \mathrm{dL} \text { ) }\end{array}$ \\
\hline
\end{tabular}

*UPr assessed by 24-hour urine collection and/or urine protein-to-creatinine ratio.

$t n=71$ out of 130 with available records.

BILAG, British isles lupus assessment group; $\mathrm{CrCl}$, creatinine clearance; CRR, complete renal remission (or response); ESRD, end-stage renal disease; GFR, glomerular filtration rate; HCQ, hydroxychloroquine; IST, immunosuppressive treatment; LR, likelihood ratio; N/D, not described; NSAID, non-steroidal anti-inflammatory drug; RBCs, red blood cells; SAlb, serum albumin; SCr, serum creatinine; SLEDAI, Systemic lupus erythematosus disease activity index; SDI, Systemic Lupus International Collaborating Clinics/American College of Rheumatology Damage Index systemic lupus international collaborating clinics (SLICC) group damage index; UPr, proteinuria.

suggested to test each of the clinical criteria with and without serology, in order to determine the usefulness of the latter and whether it adds to the construct validity of each definition.

Finally, there was consensus in the task force that treatment with antimalarials does not preclude the patient from being considered to be in remission, even though it is somewhat paradoxical to say 'off treatment' when someone is, in fact, taking a medication. However, this step was strongly supported by the task force in respect of the widely held view that antimalarials are often considered long-term maintenance therapy for patients with SLE even if they have achieved remission. Benefits of such treatment are believed to extend beyond flare prevention and disease control, and it was therefore felt incorrect to imply that these medications should be discontinued. The task force does recognise that antimalarials have immunomodulatory effects, and that therefore studies done on patients in remission 'off treatment' (by the above definition) may in some instances have to distinguish clearly between those patients who are and who are not taking antimalarials. This would perhaps seem most important for studies of an immunological or pathophysiological nature. A similar argument does of course also apply to medications that do not fall in the above categories but that have or may have immunomodulatory properties, such as statins and vitamin $\mathrm{D}$.

It was also agreed upon by all that patients who are treated with moderate-dose or high-dose glucocorticoids cannot be considered to be in remission, even if they would fulfil other criteria for remission. The main argument for this is the well-established adverse health consequence of long-term moderate-dose to high-dose glucocorticoid treatment.

Two statements were felt to be uncontroversial by the steering committee but did not achieve $>90 \%$ agreement in the larger task force. One of these, "A definition of remission in SLE must be reasonably consistent with the use of this term in the literature" was intended by the steering committee as indicating that a definition of remission must be aligned with what historically has been considered to be a remission. However, this statement was felt to be a bit too circular by some, given that the literature is divided on the definition of remission.
The statement "Durability in time can be added to any definition of remission in order to define a 'durable remission'-but need not be included in the definition of remission itself" achieved $86 \%$ agreement by premeeting electronic voting. Notably, although a few of the published definitions included in table 2 have incorporated a 'duration' component (ranging from 6 months to 5 years), the majority to the studies has not examined the prognostic importance of duration of remission against long-term patient outcomes. When discussed face-to-face by the full task force, an increasing number of delegates were unable to support this statement. After discussion, the vote was $65 \%$ in favour-not sufficient to declare consensus. The main arguments for and against this statement, as they were discussed during the meeting, are given in table 3 .

\section{The framework for a definition}

The task force discussed what form a definition of remission in SLE should take. A literature search on this topic identified many observational studies and clinical trials that used a large number of different ad hoc definitions of remission in general SLE (see online supplementary appendix table S1) and in lupus nephritis (see online supplementary appendix table S2). After extensively reviewing various options, and with particular attention to the discussion described above regarding duration, the following three key principles were agreed upon (summarised in table 4):

1. The task force achieved consensus (93\%) for the principle that remission in SLE will be defined using the following format:

"Remission in SLE is a durable state characterized by ... (followed by a reference indicating the absence of symptoms, signs or abnormal labs)".

It can be recognised that this definition is to some extent a compromise because it does not specify the length of time during which a remission would have to be sustained in order to qualify. This is a direct result of the fact that no agreement on this could be achieved and that the task force felt that further scientific studies are needed to define the optimal duration for any statement of remission in SLE. A further area of uncertainty was whether the absence of 
Table 3 Arguments for and against the statement "Durability in time can be added to any definition of remission in order to define a 'durable remission' but need not be included in the definition of remission itself"

\section{In favour of the original statement}

(ie, the definition of remission does not have to include the duration)

- Definitions of remission in other autoimmune diseases, including rheumatoid arthritis $^{35}$ and Crohn's disease, ${ }^{36}$ do not include durability

- Including durability in the definition itself would severely limit the use of the definition as an outcome in clinical trials

- Duration can always be added to the analyses in which the definition is used

SLE, systemic lupus erythematosus.

active serology would be required and yet again it was felt that this could be investigated in the future. It should therefore also be recognised that 'abnormal labs' in the above statement refers to routine laboratory assessments and not necessarily to anti-DNA antibodies or complement levels.

2. The task force spent much time on finding correct formulations for defining the absence of clinical signs and symptoms for use in a definition and agreed, in the end, that for this a validated index must be used ( $98 \%$ agreement). The task force specifically suggests that the following can be considered: clinical SLEDAI=0; BILAG 2004 D or E categories only or clinical $\mathrm{ECLAM}=0$. Furthermore, it is recommended that each of these indices is supplemented with the requirement for the physician's global assessment (PhGA) to be below a certain level: in the case of a PhGA ranging from 0 to 3 that should be $<0.5$. Note that in all instances the term 'clinical' for SLEDAI and ECLAM refers to symptoms, signs and routine laboratory testing and disregarding only the points that can be given for the presence of anti-DNA antibodies and/or low complement. The task force also discussed the possibility of defining remission in terms of specific symptoms and signs, such as was done for the proposed definition of remission in paediatric SLE, where certain symptoms and signs are 'allowed' for patients with SLE who are nevertheless considered to be in remission. ${ }^{38}$ Although a minority of participants favoured this approach, there was a more widespread feeling that not using validated indices would to some extent be retrograde, and that practice in various research settings would also increasingly be dominated by the use of such indices.

3. The task force recommends that a distinction should be made between 'remission off therapy' and 'remission on therapy' (100\% agreement). These two descriptors were chosen in preference to many other suggested terms, some of which are: 'complete' versus 'partial' remission; 'complete' versus 'clinical' remission; 'remission' versus 'lupus under control' or 'inactive disease'. While there are subtle
Against the original statement

(ie, the definition of remission does have to include the duration)

- As SLE can be remitting-relapsing, ${ }^{37}$ for a patient to be in remission at one specific point in time may not be clinically relevant

- Remission for only a short period of time has little relevance in SLE

Table 4 The task force's three key recommendations for defining remission in SLE

Key principles for defining remission in SLE

nuances differentiating between these possibilities, it was considered important to simplify this matter and to strictly limit the number of definitions to two levels of remission.

In this regard, it is also important that 'off therapy' will mean that the patient is on no other immunomodulatory treatment for SLE than possibly antimalarials. As pointed out earlier, for some studies, in particular mechanistic investigations, the immunomodulatory properties of antimalarials must be considered, and in general accurate recording of all medications is recommended.

'Remission on therapy' will allow some, but not all medications. Specifically, stable immunosuppressives, including biological immunomodulators, are allowed within this level of remission. It was noted that definitions of remission in other autoimmune diseases, including rheumatoid arthritis ${ }^{35}$ and Crohn's disease, ${ }^{36}$ do not exclude the chronic use of specific antirheumatic medications, immunosuppressives or biologics. Likewise, these definitions do not limit the use of glucocorticoids. However, in SLE a major contributor to long-term damage and other adverse outcomes is the chronic use of glucocorticoids, and the task force felt that for the patient to be declared in 'remission on treatment' the highest allowable dose of glucocorticoids is $5 \mathrm{mg} /$ day prednisone (or equivalent). Prednisone dose thresholds associated with protection from treatment-related harm are currently being studied by several groups and data from those studies should further inform the selection of a threshold glucocorticoid dose in a definition of remission on therapy.

\section{Further development of the most appropriate definition of remission}

The task force discussed in what manner a future definition of remission in SLE could be most thoroughly established.

It was agreed upon by voting that for testing the construct validity of each potential remission definition the most

1. Definitions of remission in SLE will be worded as follows: Remission in SLE is a durable state characterized by symptoms, signs, routine labs)

- Requirement for serology may be added

2. For defining remission in SLE, a validated index must be used

- Suggested indices are: clinical SLEDAI=0; BILAG 2004 D or E only; clinical ECLAM $=0$

- These must be supplemented by the physician's global assessment being below an appropriate threshold (eg, $<0.5$ on a $0-3$ scale)

3. A distinction will be made between remission off therapy and remission on therapy

- Remission off therapy requires the patient to be on no other treatment for SLE than maintenance antimalarials

- Remission on therapy allows patients to be treated with maintenance antimalarials, stable, low-dose glucocorticoids (eg, prednisone $\leq 5 \mathrm{mg} /$ day), maintenance immunosuppressives and/or stable (maintenance) biologics

Agreement

$93 \%(2$

abstained)

$98 \%$

ECLAM, European consensus lupus outcome measure; SLE, systemic lupus erythematosus. 
appropriate outcomes are death, damage, lupus flares and HR-QOL measures (100\% agreement).

Thus, the task force indicated that any definition of remission in SLE must be tested in terms of the degree to which it correctly identifies patients whose future disease course will be better in these four outcomes. Although mortality remains a key outcome, it is unlikely that many studies will be able to identify this as a differentiating factor. Damage as measured by the systemic lupus international collaborating clinics (SLICC) damage index ${ }^{39}$ will most likely be the most effective way of ascertaining the construct validity of a definition of remission, as has been provisionally demonstrated for the definition of LLDAS. However, the occurrence of flares, especially severe flares, that can be measured by a variety of instruments, ${ }^{40-42}$ and measures of HR-QoL will also be important in determining which potential definition of remission in SLE has the greatest validity.

\section{Other points of discussion}

Patient's global assessment

There was controversy about the role of the patient's global assessment (PGA) in a remission definition. A majority felt that PGA cannot currently be included pending further research, and specifically that such research is needed to validate PGA as an outcome in reference to remission. Many felt that a better instrument to capture the patient's perspective may be needed. However, patient representatives (authors KL, CC and $\mathrm{BvL}$ ) were concerned that the patient's perspective was omitted. Indeed, in the T2T recommendations for SLE, both overarching principles and specific recommendations advocate including the patient's perspective in decision-making. However, there is no fully validated measure for the patient's perspective at this time. It was remarked that the PhGA can reflect patient's perspective, and it was proposed to emphasise that PhGA should pay careful attention to patient symptoms, or conversely, that PGA could be a long-term outcome used in the testing of remission definitions; but in formal votes no consensus was reached on these points.

\section{Inclusion of validated skin score}

The dermatologists in the task force (authors AK and VPW) suggested to supplement the definition of remission with a validated skin score.

\section{Definition based only on symptoms}

A rheumatologist (author MW) pointed out that in as much as the task force is developing possible definitions of remission, a definition based only on symptoms and without the use of an index could also be tested.

\section{Plans for further work and research agenda}

The task force agreed upon a plan of work that would include the use of longitudinal datasets from clinical trials, observational studies, registries, etc to test each of the definitions of remission. Likewise, definitions of remission 'on treatment' and 'off treatment' will be tested separately against the prespecified dependent outcomes indicated above, and different durations of these definitions will also be tested. Moreover, studies done on patients 'off treatment' will also record the use of antimalarials and analyse the extent to which this makes a difference. As always, findings in such subanalyses may inform future changes in the proposed definitions.

Proposed durations to be analysed include 6 months, 12 months, 2 years and 5 years.
In addition to this continued work, the task force also recommends specific research to investigate whether definitions of remission are applicable irrespective of genetic backgrounds and/or ethnicity.

\section{DISCUSSION}

An international task force consisting of patient representatives and specialists in clinical immunology, dermatology, nephrology and rheumatology was convened and achieved high-level agreement on eight statements, three key principles and a set of outcomes relating to remission in SLE, thereby providing a road map for further work towards a generally applicable definition.

Remission was approached as a global state, whereas it is recognised that remission can be defined, and has in some instances been defined, at the individual organ system level.

As a conceptual starting-point remission was identified as a desirable outcome for patients with SLE with at the very least the absence of major symptoms and signs of SLE. Remission is considered distinct from a cure and it is also regarded as meaningfully different from a state of low disease activity in SLE such as the LLDAS that has recently been developed by the Asia-Pacific Lupus Collaboration. ${ }^{5}$ However, the latter definition does not solely require the presence of low disease activity and does therefore, in fact, include both patients who have a low level of disease activity and also those who are in remission.

Perhaps most critically for future work in this area, it is recognised that remission has to be a state that, if sustained, is associated with a low likelihood of adverse outcome.

Regarding treatment, there was consensus that treatment with antimalarials does not preclude the patient from being considered to be in remission, in respect of the recommendation that antimalarials should be considered as long-term maintenance therapy for patients with SLE even if they have achieved remission. ${ }^{3}$ It was also agreed upon by all that patients who are treated with moderate-dose or high-dose glucocorticoids cannot be considered to be in remission even if they would fulfil other criteria for remission. It is well established that glucocorticoids may suppress signs of disease, but will not achieve bona fide disease control, and also constitute one of the major risk factors for negative outcomes in SLE.

In contrast to these areas of agreement, no consensus could be achieved on two important issues.

First, it transpired that the inclusion of 'duration' in a definition of remission was controversial. Some argued that definitions of remission in other disease areas do not have this requirement, and that utility of a definition in clinical studies including clinical trials will be significantly limited if duration is explicitly required. Others argued that remission achieved on only one given point in time lacks clinical relevance in a disease that can be relapsing and remitting. Following lengthy discussion, the task force was able to agree on a compromise using the wording "Remission is a durable state characterised by...." and also clearly identified the need for studies linking the duration of any definition of remission with long-term outcomes.

Second, the task force did not agree on the precise role of the PGA in a remission definition. This issue was debated at considerable length. Several task force members including patient representatives were concerned that the patient's perspective was not explicitly included in the definition, and emphasised the importance of a definition of remission that 'resonates' with the patient. However, a majority of the task force felt that while the patient's perspective is critically important in the patientphysician interaction, when it comes to a definition of remission for the purposes of clinical and epidemiological studies and 
clinical trials, more work is needed in order to either validate PGA as an outcome or more likely to develop a better instrument to capture the patient's perspective. It was pointed out that the physician, when assessing disease activity, is expected to weigh in the patient's perspective.

Additionally, the task force agreed on the definition of 'serological activity,' but no consensus was reached regarding whether the latter should be taken into account to define remission. The task force agreed upon the use of longitudinal datasets to determine whether serology adds to the construct validity of each definition.

Nomenclature for remission in SLE was extensively discussed. Many terms were proposed, including 'complete remission', 'partial' 'remission', 'clinical remission', 'serological remission', 'lupus under control', 'inactive disease,' etc, many of which were overlapping. In order to simplify matters and achieve consistency, the task force recommends that only one distinction is made between 'remission off therapy' and 'remission on therapy', where 'off therapy' must mean that the patient is on no systemic treatments for SLE other than antimalarials. While 'remission on antimalarials only' would be the most accurate term for this state, 'remission off therapy' was chosen for brevity and convenience, even though it does allow antimalarial therapy. As stated previously, it will be necessary in future studies to account for the actual use of antimalarials in this group of patients, and subsequent analyses of patients who are and who are not on antimalarials may lead to further distinctions in these categories.

'Remission on therapy' will allow stable immunosuppressives, including biologics, and low-dose glucocorticoids. It is of interest to note that the latter type of definition is the more usual in other autoimmune diseases, such as rheumatoid arthritis and Crohn's disease, and would also allow investigators to use the definition in clinical trials.

One limitation of the approach taken by the task force is the decision to limit serological activity to anti-DNA antibodies and low complement. Recent research shows the importance of antibodies to RNA binding proteins to the formation of immune complexes that can stimulate interferon production. Further research may show that, unless these antibodies are assayed, the serological assessment is incomplete.

Finally, the task force recommends a clear research agenda of testing the construct validity of potential remission definitions against death, damage, lupus flares and HR-QOL measures as outcomes (dependent variables) in suitable cohorts of patients. Several task force members have conducted or are conducting such studies. This approach will establish which definition(s) of remission in SLE optimally identifies patients with a better disease course in these four outcomes.

In summary, a set of statements and key principles relevant to remission in SLE were established by an international task force. This work provides a pathway for testing individual definitions against long-term outcomes in order to arrive at a definition of remission in SLE.

\section{Author affiliations}

Department of Medicine, Unit for Clinical Therapy Research, Inflammatory Diseases (ClinTRID), Karolinska Institutet, D1:00 Karolinska University Hospital, Solna, Stockholm, Sweden

${ }^{2}$ Amsterdam Rheumatology and Immunology Center, VU University Medical Center, Amsterdam, The Netherlands

${ }^{3}$ Department of Rheumatology, Clinical Immunology and Allergy, University of Crete School of Medicine, Iraklion, Greece

${ }^{4}$ Feinstein Institute for Medical Research, Manhasset, New York, USA

${ }^{5}$ Department of Medicine III, University Medical Center TU Dresden, Dresden, Germany
}

${ }^{6}$ New York University, New York, USA

${ }^{7}$ LPRe SR-Klub Motýlik, Bratislava, Slovakia

${ }^{8}$ Rheumatology Division, Faculdade de Medicina da Universidade de São Paulo, São Paulo, Brazil

${ }^{9}$ Department of Rheumatology and Clinical Immunology, University of Groningen, University Medical Center Groningen, Groningen, The Netherlands

${ }^{10}$ Department of Medicine and Joint Academic Rheumatology Program Medical

School, National and Kapodestrian University of Athens, Athens, Greece

${ }^{11} \mathrm{NIHR}$ Manchester Biomedical Research Unit, The University of Manchester and Central Manchester Foundation Trust, Manchester, UK

${ }^{12}$ Department of Autoimmune Diseases, Hospital Clinic, Barcelona, Catalonia, Spain

${ }^{13}$ Division of Rheumatology, The Arthritis Society Chair in Rheumatic Diseases

Cumming School of Medicine University of Calgary, Calgary, Alberta, Canada

${ }^{14}$ Lupus Foundation of America, Washington DC, USA

${ }^{15}$ Université Paris-Decartes, Paris, France

${ }^{16}$ AP-HP, Hôpital Cochin, service de médecine interne, centre de reference maladies auto-immunes et systémiques rares, Paris, France

${ }^{17}$ Department of Rheumatology and Immunology, Institute of Bioanalysis, Institute of Family Medicine, University of Pécs, Pécs, Hungary

${ }^{18}$ Third Department of Internal Medicine, Semmelweis University, Budapest, Hungary

${ }^{19}$ Department Rheumatology and Clinical Immunology, University Medical Center

Utrecht, The Netherlands

${ }^{20}$ Rheumatology Unit, Department of Medicine, University of Padova, Padova, Italy

${ }^{21}$ Department Medicine/Rheumatology and Clinical Immunology, Charite

Universitätsmedizin Berlin, Berlin, Germany

${ }^{22}$ Polyclinic of Rheumatology, Hiller Research Unit, University Clinic Duesseldorf,

Heinrich-Heine-University, Duesseldorf, Germany

${ }^{23}$ Rheumatology Research Group, Institute of Inflammation and Ageing, College of

Medical and Dental Sciences, University of Birmingham, Birmingham, UK

${ }^{24}$ Division of Rheumatology, Medical University of Graz, Graz, Austria

${ }^{25}$ Service de Rhumatologie, Cliniques universitaires Saint-Luc, Pôle de pathologies

rhumatismales inflammatoires et systémiques, Institut de Recherche Expérimentale et

Clinique, Université catholique de Louvain, Bruxelles, Belgium

${ }^{26}$ Department of Medicine, The Centre for Rheumatology, University College London, UK

${ }^{27}$ Copenhagen Lupus and Vasculitis Clinic, Center for Rheumatology and Spine

Diseases, Copenhagen, Denmark

${ }^{28}$ Department of Medicine, University of Cambridge, Cambridge, UK

${ }^{29}$ Interdisciplinary Center for Clinical Trials (IZKS), University Medical Center Mainz,

Mainz, Germany

${ }^{30}$ LUPUS EUROPE, co-opted trustee for research, Essex UK

${ }^{31}$ Rheumatology Department, Universidade do Estado do Rio de Janeiro, Rio de

Janeiro, Brazil

${ }^{32}$ Université Paris-Sud; Assistance Publique-Hôpitaux de Paris, Hôpitaux

Universitaires Paris-sud; INSERM U1184, Le Kremlin Bicêtre, France

${ }^{33}$ Bone Densitometry Unit, Monla Hospital, Tripoli, Lebanon

${ }^{34}$ Monash University, Faculty of Medicine, Nursing \& Health Sciences, Monash

Medical Centre, Clayton, Australia

${ }^{35}$ Rheumatology Unit, Department of Clinical and Experimental Medicine, University

of Pisa, Pisa, Italy

${ }^{36}$ Department of Internal Medicine, Division of Rheumatology, Istanbul University,

Istanbul Medical Faculty, Istanbul, Turkey

${ }^{37}$ University of Santo Tomas, Manila, Philippines

${ }^{38}$ Vasculitis.at, Vienna, Austria

${ }^{39}$ Department of Connective Tissues Diseases, National Institute of Geriatrics,

Rheumatology and Rehabilitation, Warsaw, Poland

${ }^{40}$ Johns Hopkins University School of Medicine, Baltimore, Maryland, USA

${ }^{41}$ RNA and Molecular Pathology Research Group, Institute of Medical Biology,

Health Science Faculty, University of Tromsø, Tromsø, Norway

${ }^{42}$ National Institute for Rheumatic Diseases, Pieštany, Slovak Republic

${ }^{43}$ Zabludowicz Center for Autoimmune Diseases, Sheba Medical Center (Affiliated to

Tel-Aviv University), Tel-Aviv, Israel

${ }^{44}$ Division of Rheumatology, Department of Medicine 3, Medical University of

Vienna, Vienna, Austria

${ }^{45}$ 2nd Department of Medicine, Hietzing Hospital, Vienna, Austria

${ }^{46}$ Dipartimento di Scienze Cliniche e Sperimentali, Università degli Studi di Brescia,

U.O. Reumatologia e Immunolgia Clinica, Spedali Civili di Brescia, Brescia, Italy

${ }^{47}$ Centre for Prognosis Studies in the Rheumatic Diseases, Senior Scientist Krembil

Research Institute, Professor Medicine, University of Toronto, Toronto Western

Hospital EW 1-409, Toronto, Canada

${ }^{48}$ Unidade de Imunologia Clínica, Hospital Santo António, Centro Hospitalar do Porto, UMIB, Instituto de Ciencias Biomédicas Abel Salazar, Universidade do Porto, Porto, Portugal

${ }^{49}$ Department of Rheumatology, Odense University Hospital, University of Southern Denmark, Denmark

${ }^{50}$ Corporal Michael J. Crescenz VA Medical Center (Philadelphia), Philadelphia,

Philadelphia, USA 
${ }^{51}$ Department of Dermatology, Perelman School of Medicine, University of Pennsylvania, Philadelphia, USA

${ }^{52}$ Nephrology Unit, City Clinical Hospital n.a. S.P. Botkin, Moscow, Russia

${ }^{53}$ Lanarkshire Centre for Rheumatology, Hairmyres Hospital, Scotland, UK

${ }^{54}$ National Institute of Arthritis and Musculoskeletal and Skin Diseases, National Institutes of Health, Bethesda, Maryland, USA

Twitter Follow Dimitrios T Boumpas at @none

Acknowledgements The authors wish to acknowledge Ms Lisbeth Löfstrand, Administrator at Karolinska Institutet for her invaluable help during the organisation of the DORIS meetings as well as for manuscript preparation.

Competing interests RvVreports having received Research Support and Grants from AbbVie, Amgen, BMS, GSK, Pfizer, Roche, UCB, and Consultancy or honoraria from AbbVie, Biotest, BMS, Celgene, Crescendo, GSK, Janssen, Lilly, Merck, Novartis, Pfizer, Roche, UCB, Vertex. LAreports having received travel grants, consultancy or honoraria from Adelphivalues, Amgen, Eli Lilly, GSK, LFB, Menarini France, MSD, Raison de santé.

Provenance and peer review Not commissioned; externally peer reviewed.

\section{REFERENCES}

1 Houssiau FA, Vasconcelos C, D'Cruz D, et al. The 10-year follow-up data of the Euro-Lupus Nephritis Trial comparing low-dose and high-dose intravenous cyclophosphamide. Ann Rheum Dis 2010;69:61-4.

2 Bexelius C, Wachtmeister K, Skare P, et al. Drivers of cost and health-related quality of life in patients with systemic lupus erythematosus (SLE): a Swedish nationwide study based on patient reports. Lupus 2013;22:793-801.

3 van Vollenhoven RF, Mosca M, Bertsias $G$, et al. Treat-to-target in systemic lupus erythematosus: recommendations from an international task force. Ann Rheum Dis 2014;73:958-67.

4 Steiman AJ, Urowitz MB, Ibañez $\mathrm{D}$, et al. Prolonged clinical remission in patients with systemic lupus erythematosus. J Rheumatol 2014;41:1808-16.

5 Franklyn K, Lau CS, Navarra SV, et al. Definition and initial validation of a Lupus Low Disease Activity State (LLDAS). Ann Rheum Dis 2016;75:1615-21.

6 Drenkard C, Villa AR, Garcia-Padilla C, et al. Remission of systematic lupus erythematosus. Medicine (Baltimore) 1996;75:88-98.

7 Nossent J, Kiss E, Rozman B, et al. Disease activity and damage accrual during the early disease course in a multinational inception cohort of patients with systemic lupus erythematosus. Lupus 2010;19:949-56.

8 Zen M, laccarino L, Gatto M, et al. Prolonged remission in Caucasian patients with SLE: prevalence and outcomes. Ann Rheum Dis 2015;74:2117-22.

9 Medina-Quiñones CV, Ramos-Merino L, Ruiz-Sada P, et al. Analysis of complete remission in systemic lupus erythematosus patients over a 32 years period. Arthritis Care Res (Hoboken) 2016;68:981-7.

10 Moroni G, Quaglini S, Maccario M, et al. "Nephritic flares" are predictors of bad long-term renal outcome in lupus nephritis. Kidney Int 1996;50:2047-53.

11 Mok CC, Wong RW, Lau CS. Lupus nephritis in Southern Chinese patients: clinicopathologic findings and long-term outcome. Am I Kidney Dis 1999;34:315-23.

12 Korbet SM, Lewis EJ, Schwartz MM, et al. Factors predictive of outcome in severe lupus nephritis. Lupus Nephritis Collaborative Study Group. Am I Kidney Dis 2000;35:904-14.

13 Najafi CC, Korbet SM, Lewis EJ, et al. Significance of histologic patterns of glomerular injury upon long-term prognosis in severe lupus glomerulonephritis. Kidney Int 2001;59:2156-63.

14 Chen YE, Korbet SM, Katz RS, et al. Value of a complete or partial remission in severe lupus nephritis. Clin J Am Soc Nephrol 2008:3:46-53.

15 Illei GG, Takada K, Parkin D, et al. Renal flares are common in patients with severe proliferative lupus nephritis treated with pulse immunosuppressive therapy: long-term follow-up of a cohort of 145 patients participating in randomized controlled studies. Arthritis Rheum 2002:46:995-1002.

16 Hill GS, Delahousse M, Nochy D, et al. Outcome of relapse in lupus nephritis: roles of reversal of renal fibrosis and response of inflammation to therapy. Kidney Int 2002;61:2176-86

17 Mok CC, Ying KY, Tang S, et al. Predictors and outcome of renal flares after successful cyclophosphamide treatment for diffuse proliferative lupus glomerulonephritis. Arthritis Rheum 2004;50:2559-68.
18 Mok CC, Ying KY, Ng WL, et al. Long-term outcome of diffuse proliferative lupus glomerulonephritis treated with cyclophosphamide. Am J Med 2006;119:355.e25-33.

19 Moroni G, Quaglini S, Gallelli B, et al. The long-term outcome of 93 patients with proliferative lupus nephritis. Nephrol Dial Transplant 2007:22:2531-9.

20 Mak A, Mok CC, Chu WP, et al. Renal damage in systemic lupus erythematosus: a comparative analysis of different age groups. Lupus 2007;16:28-34.

21 Lee BS, Cho HY, Kim EJ, et al. Clinical outcomes of childhood lupus nephritis: a single center's experience. Pediatr Nephrol 2007:22:222-31.

22 Sun HO, Hu WX, Xie HL, et al. Long-term outcome of Chinese patients with membranous lupus nephropathy. Lupus 2008;17:56-61.

23 Ayodele OE, Okpechi IG, Swanepoel CR. Predictors of poor renal outcome in patients with biopsy-proven lupus nephritis. Nephrology (Carlton) 2010;15: 482-90.

24 So MW, Koo BS, Kim YG, et al. Predictive value of remission status after 6 months induction therapy in patients with proliferative lupus nephritis: a retrospective analysis. Clin Rheumatol 2011;30:1399-405.

25 Reich HN, Gladman DD, Urowitz MB, et al. Persistent proteinuria and dyslipidemia increase the risk of progressive chronic kidney disease in lupus erythematosus. Kidney Int 2011:79:914-20.

26 Alsuwaida A, Husain $S$, Alghonaim $M$, et al. Strategy for second kidney biopsy in patients with lupus nephritis. Nephrol Dial Transplant 2012;27:1472-8.

27 Dhir V, Aggarwal A, Lawrence A, et al. Long-term outcome of lupus nephritis in Asian Indians. Arthritis Care Res (Hoboken) 2012;64:713-20.

28 Moroni G, Quaglini S, Gravellone L, et al. Membranous nephropathy in systemic lupus erythematosus: long-term outcome and prognostic factors of 103 patients. Semin Arthritis Rheum 2012:41:642-51.

29 Mahmoud GA, Zayed HS, Ghoniem SA. Renal outcomes among Egyptian lupus nephritis patients: a retrospective analysis of 135 cases from a single centre. Lupus 2015:24:331-8

30 Fernandes das Neves M, Irlapati RV and Isenberg D. Assessment of long-term remission in lupus nephritis patients: a retrospective analysis over 30 years. Rheumatology (Oxford) 2015;54:1403-7.

31 Koo HS, Kim S, Chin HJ. Remission of proteinuria indicates good prognosis in patients with diffuse proliferative lupus nephritis. Lupus 2016;25:3-11.

32 Dall'Era M, Cisternas MG, Smilek DE, et al. Predictors of long-term renal outcome in lupus nephritis trials: lessons learned from the Euro-Lupus Nephritis cohort. Arthritis Rheumatol 2015:67:1305-13.

33 Tamirou F, D'Cruz D, Sangle S, et al. Long-term follow-up of the MAINTAIN Nephritis Trial, comparing azathioprine and mycophenolate mofetil as maintenance therapy of lupus nephritis. Ann Rheum Dis 2016;75:526-31.

34 Tamirou F, Lauwerys BR, Dall'Era M, et al. A proteinuria cut-off level of $0.7 \mathrm{~g} /$ day after 12 months of treatment best predicts long-term renal outcome in lupus nephritis: data from the MAINTAIN Nephritis Trial. Lupus Sci Med 2015;2: e000123.

35 Felson DT, Smolen IS, Wells G, et al. American College of Rheumatology/European League against Rheumatism provisional definition of remission in rheumatoid arthritis for clinical trials. Ann Rheum Dis 2011;70:404-13.

36 Best WR, Becktel JM, Singleton JW, et al. Development of a Crohn's disease activity index. National Cooperative Crohn's Disease Study. Gastroenterology 1976:70:439-44.

37 Barr SG, Zonana-Nacach A, Magder LS, et al. Patterns of disease activity in systemic lupus erythematosus. Arthritis Rheum 1999;42:2682-8.

38 Mina R, Klein-Gitelman MS, Ravelli A, et al. Inactive disease and remission in childhood-onset systemic lupus erythematosus. Arthritis Care Res 2012;64:683-93.

39 Gladman D, Ginzler E, Goldsmith C, et al. The development and initial validation of the Systemic Lupus International Collaborating Clinics/American College of Rheumatology damage index for systemic lupus erythematosus. Arthritis Rheum 1996;39:363-9.

40 Gordon C, Sutcliffe N, Skan J, et al. Definition and treatment of lupus flares measured by the BILAG index. Rheumatology (Oxford) 2003;42 1372-9.

41 Merrill J, Buyon J, Furie R, et al. Assessment of flares in lupus patients enrolled in a phase II/III study of rituximab (EXPLORER). Lupus 2011;20:709-16.

42 Isenberg DA, Allen $E$, Farewell $V$, et al. An assessment of disease flare in patients with systemic lupus erythematosus: a comparison of BILAG 2004 and the flare version of SELENA. Ann Rheum Dis 2011:70:54-9. 